\title{
A Decision Support System for Estimating Allowable Soil Bearing Capacity for Mobile Crane Work
}

\author{
Ghulam Muhammad Ali ${ }^{1 * *}$, Asif Mansoor ${ }^{1}$, Shuai Liu ${ }^{1}$, Ahmed Bouferguene ${ }^{2}$, and Mohamed Al-Hussein ${ }^{1}$ \\ ${ }^{1}$ Department of Civil and Environmental Engineering, University of Alberta, Edmonton, Canada \\ ${ }^{2}$ Campus Saint-Jean, University of Alberta, Edmonton, Canada \\ "gmali@ualberta.ca
}

\begin{abstract}
The use of modular construction burgeoned mobile cranes' impact on construction sites, which has led to the manufacturing of heavier modules with weights often measured in hundreds of tons. Because of the surge in module weight, mobile cranes are predominant, ensuring adequate ground stability under the lifting equipment since its debacle can have dire repercussions for the workers and the project. The traditional approach is to make use of timber/steel mats for ground stability. Before that, it is crucial to estimate the allowable soil bearing capacity as a prerequisite to reckon the compensation for deficient ground support. The crane rental companies' status quo approach collects this information from the client without incorporating mobile crane track/outrigger surface area (crawler crane track/mat, hydraulic crane outrigger mat). This contribution aims to develop a Visual basic computer application to determine soil's allowable soil bearing capacity for crane work. The developed application consolidates mobile crane footing area and computes allowable soil bearing capacity based on the soil data from a construction site's geotechnical reports. The developed application uses soil bearing capacity theorems (e.g., Terzaghi, Meyerhof, Hansen, and Vesic) for the calculations. The developed application will help practitioners estimate the allowable soil bearing capacity with the crane mat surface area to complement the information received from the clients.
\end{abstract}

Keywords: Allowable soil bearing capacity, mobile cranes, crane mats, geotechnical reports.

\section{Introduction}

The modern heavy construction industry is increasingly adopting modularization. The concept of modular construction proceeds by splitting large and complex projects into small modules manufactured indoors in controlled environments. While many motives have paved the way for modular construction, the most cost-effective of these is the possibility of shifting a significant portion of the work from construction sites to an indoor offsite environment [1]. Further, environmental, economic, and social factors also serve as significant drivers for adopting modular construction [2]. With this regard, the projects are broken down into modules fabricated independently, leaving a single activity to be carried out outdoors, the assembly of these modules. Modularization encouraged engineers and designers to front-load these modules with maximum functionalities to minimize the onsite construction work. With the surge in functionalities, the weight of modules also increased, from tens to hundreds of tons. The increase in module weight led to a demand for specialized resources, especially those relevant to high-capacity cranes. However, this high capacity is equivalent to increased structural complexity and heavier crane weights. For the safe operation of high-capacity cranes on a construction site, the first consideration on the table is to ensure that the bearing capacity of the ground underneath the crane can accommodate the pressure exerted by the crane and payload compound weight. It is worth noting that most crane-related accidents on construction sites are linked to soil stability (11\%), and mobile crane fatalities account for (approximately) $84 \%$ of all the fatalities involving cranes/derricks [3]. The number of accidents linked with soil stability shows that proper estimation of allowable soil bearing capacity is essential for a safe lift. In case of poor soil support, the crane track/outrigger/mat can sink in the ground, resulting in crane tipping leading to an unreversible chain reaction of crane overturning. Figure 1 shows an example of crane tipping in general. Due to the poor ground support, the crane track presses the ground at the front, resulting in the rear track rollers leaving the track and ground.

For crane work, it is critical to prepare the ground for safe crane lifting activities. The status quo approach is to prepare the ground by backfilling with aggregate and compacting it to make it suitable for crane work (as shown in Figure 2). In most cases, an extra layer of crane mats is used underneath the mobile cranes to increase the safety of the crane operation. 
The whole exercise of area preparation can become expensive if the practitioners do not adequately calculate soil bearing capacity to judge the soil stability.

Considering the ultimate soil bearing capacity calculations, in 1857, Rankine proposed the first-ever approach [4]. Later, Terzaghi [5] presented a formula to calculate the ultimate soil bearing capacity under a foundation. The crane track/outrigger/mat works as a foundation for ultimate soil bearing capacity calculations for crane work. Meyerhof [6] further refined the equation to add some factors. Later, Hansen [7] and Vesic [8] refined these factors to develop and refine the soil bearing capacity equation.

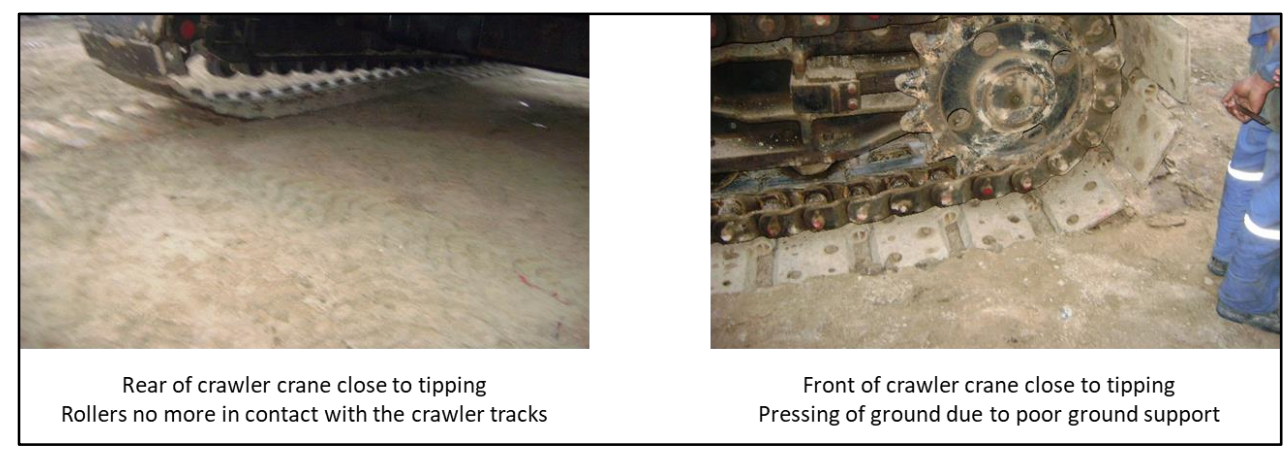

Fig. 1: Crane tipping due to poor ground support.

The traditional status quo approach for the value of allowable soil bearing capacity for the crane rental companies is to use the information provided by the client. This approach lacks integration of crane tracks/outriggers/mats, impacting the allowable soil bearing capacity [4], [9]-[12]. The current manuscript utilizes the equations developed by Terzaghi [5], Meyerhof [6], Hansen [7], and Vesic [8] to calculate the soil bearing capacity. For the foundation design and construction stability, these soil bearing capacity calculation approaches are used widely by practitioners in the construction industry [12]. In this contribution, a computer application is developed in Visual Basic to calculate allowable soil bearing capacity as per the site requirement. The developed application will assist the practitioners in estimating the allowable soil bearing capacity for crane work. Based on the values obtained from this application, practitioners will evaluate the ground preparation requirement, as shown in Figure 2. In addition to the capacity profiles paramount for safety, the developed application also allows practitioners to save time and cost associated with the area preparation. The results of various case examples (using the developed application) suggest that the allowable soil bearing capacity varies with the crane track/outrigger/mat width, and it is not constant for every type of crane work. The developed methodology in the application provides a better understanding of soil bearing capacity underneath various mobile cranes. For the operability of the developed application, it is crucial to have a geotechnical report of the construction site to obtain the soil data required for the computation. However, if the geotechnical data is not required (or not available), a rough estimate for each required variable is also provided in this contribution for the ease of practitioners.

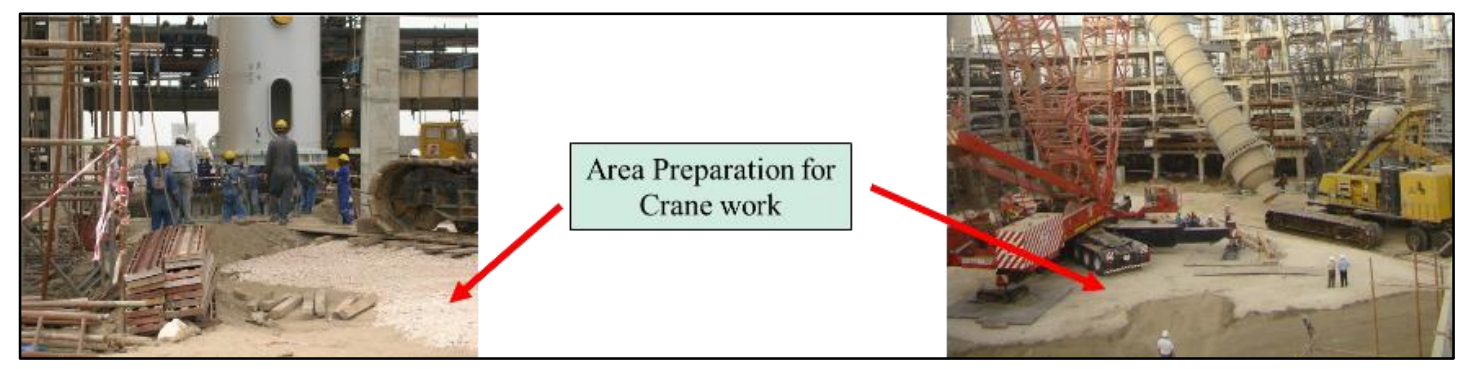

Fig. 2: Area preparation for crane work to avoid ground settling and crane tipping. 


\section{Methodology}

The ultimate soil bearing capacity $q_{u}$, also known as geotechnical bearing resistance at the ultimate limit state is shown shown in Figure 3 [13]. The resistance of soil balances the pressure exerted by the crane combined loading. The soil cohesion cohesion and weight of soil exert pressure to stabilize the crane to avoid track/outrigger/mat sinking. Many researchers developed equations to estimate the ultimate soil bearing capacity. The current contribution compares four practical approaches to provide a result in the form of computer application output.

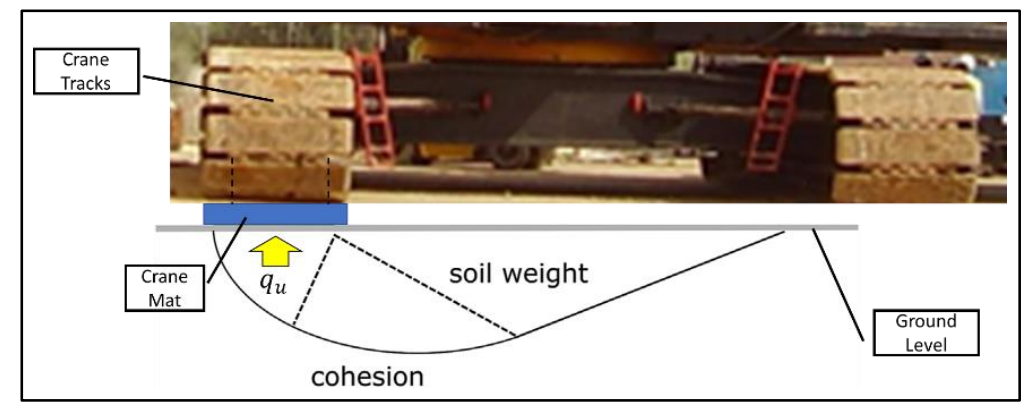

Fig. 3: Ultimate ground bearing pressure to counter crane loading (Ground bearing pressure).

\subsection{Development of allowable soil bearing capacity equations}

The methodology developed by the authors of this contribution relies on four basic approaches for soil bearing capacity calculations. These approaches are derived from Terzaghi [5], Meyerhof [6], Hansen [7], and Vesic [8] soil bearing capacity estimation work. For foundation design, the construction industry widely uses these four approaches. These four approaches are as below:

\subsubsection{Terzaghi (1943)}

Terzaghi [5] formulated an equation to estimate the ultimate soil bearing capacity based on general shear failures of shallow strip footings [14], [15]. He developed the primary form of the equation as shown in Eq. 1.

$$
q_{u}=c N_{c}+q_{s} N_{q}+\frac{1}{2} \gamma B N_{\gamma}
$$

Where $c$ is soil cohesion, $N_{c}, N_{q}, N_{\gamma}$ are dimensionless bearing capacity factors, $q_{s}$ is vertical stress at the elevation of the base of crane track/outrigger/mat, $\gamma$ is soil unit weight, and $B$ is the least plan dimension of crane track/outrigger/mat. Eq. 1 by Terzaghi [5] is for the strip footing beneath the ground level, but for crane work, the crane track/outrigger/mat is always above the ground level, and the value of $q_{s}$ diminishes to zero. This change shows that only cohesion and soil weight impacts the soil bearing capacity, as shown in Figure 3.

To calculate the allowable soil bearing capacity $q_{a l l}$, the factor of safety $F S$ is integrated into the Eq. 1 to form Eq. 2 . The value of the safety factor is usually based on onsite construction requirements and usually varies between 2 to 5 .

$$
q_{\text {all }}=\frac{q_{u}}{F S}
$$

The developed application calculates the dimensionless bearing capacity factors using the following equations based on internal friction angle $\emptyset$.

Where $a=e^{(0.75 \pi-\emptyset / 2) \tan \varnothing}$.

$$
N_{q}=\frac{a^{2}}{2 \cos ^{2}(\pi / 4+\emptyset / 2)}
$$

$$
\begin{gathered}
N_{c}=\left(N_{q}-1\right) \cot \emptyset \\
N_{\gamma}=\frac{\tan \emptyset}{2}\left(\frac{K_{p \gamma}}{\cos ^{2} \emptyset}-1\right)
\end{gathered}
$$


Where $K_{p \gamma}=$ passive pressure coefficient. It is also important to mention that $N_{c}=5.7$ when $\emptyset=0$. In Terzaghi's approach [5], the value of $K_{p \gamma}$ is determined by means of a graphical method. Later Coduto [14] presented a way to the value of $K_{p \gamma}$ numerically using the following equation.

$$
N_{\gamma} \approx \frac{2\left(N_{q}+1\right) \tan \emptyset}{1+0.4 \sin (4 \varnothing)}
$$

\subsubsection{Meyerhof (1963)}

Meyerhof [6], [16] refined Eq. 1 by adding dimensionless modification factors to make it closer to reality. The equation below describes the modifications proposed by Meyerhof.

$$
q_{u}=c N_{c} S_{c}+q_{s} N_{q} S_{q}+\frac{1}{2} \gamma N_{\gamma} B S_{\gamma}
$$

Where $S_{c}, S_{c}, S_{c}$ are dimensionless modification factors for crane track/outrigger/mat shape, inclination, depth, tilt, and ground slope. The modified dimensionless factors reported by Meyerhof are as follow [6], [13], [16]:

$$
\begin{gathered}
N_{q}=e^{\pi \tan \varnothing} \tan ^{2}(\pi / 4+\emptyset / 2) \\
N_{c}=\left(N_{q}-1\right) \cot \emptyset \\
N_{\gamma}=\left(N_{q}-1\right) \tan (1.4 \varnothing) \\
S_{c}=1+0.2 \tan ^{2}(\pi / 4+\emptyset / 2) \frac{B}{L} \\
S_{q}=S_{\gamma}=1, \quad \text { for } \emptyset=0 \\
S_{q}=S_{\gamma}=1-0.1 \tan ^{2}(\pi / 4+\emptyset / 2) \frac{B}{L} \quad \text { for } \emptyset>0
\end{gathered}
$$

Where $B$ is the width of the crane track/outrigger/mat and $L$ is the length of the crane track/outrigger/mat.

\subsubsection{Hansen (1970)}

Hansen [7] also presented modifications and adjustments to the ultimate soil bearing capacity equation (Eq. 7). Hansen presented some modifications to the values of $N_{\gamma}, S_{c}, S_{q} \& S_{\gamma}$ as below:

$$
\begin{gathered}
N_{\gamma}=1.5\left(N_{q}-1\right) \tan \emptyset \\
S_{c}=1+\frac{N_{q} B}{N_{c} L} \\
S_{q}=1+\frac{B}{L} \sin \emptyset \\
S_{\gamma}=1-0.4 \frac{B}{L}
\end{gathered}
$$

\subsubsection{Vesic (1975)}

Vesic [8] further modified the ultimate soil bearing capacity equation (Eq. 7) and updated the values of $N_{\gamma} \& S_{q}$ as below:

\subsection{Development of $A S B C$}

$$
\begin{gathered}
N_{\gamma}=2\left(N_{q}-1\right) \tan \emptyset \\
S_{q}=1+\frac{B}{L} \tan \varnothing
\end{gathered}
$$

The authors of this contribution developed an application named $A S B C$ (Allowable soil bearing capacity calculator for mobile cranes). Figure 4 shows the appearance of $A S B C$. The practitioner must provide the values of $L, B, \emptyset, c, \gamma \& F S$, so that the application can calculate accordingly. The application $A S B C$ provides dimensionless factors values under each approach and provides the allowable soil bearing capacity value using each approach as mentioned 
in section 2.1. The final values are in the units of Metric Ton $/ \mathrm{m}^{2}$. Figure 5 shows the flowchart of the processes involved in calculating allowable soil bearing capacity.

\section{Case Examples}

\subsection{Soil parameters for allowable soil bearing capacity}

The prerequisites for the application are the values of $L, B, \emptyset, c, \gamma$ and $F S$. The dimensions of the crane track/outrigger/mat of the crane used for the crane lift provide the values of $L$ and $B$. The value of $F S$ is perceived between $2 \sim 5$ and depends mainly on the construction site constraints. The main concern is the values of $\emptyset, c$ and $\gamma$, which geotechnical reports of the construction site can provide. Usually, the geotechnical reports provide the values of shear strength of soil $S_{u}$ and unit soil weight $\gamma$, and in some cases the value of $\emptyset$. In case the value of shear strength is provided, Coulomb's equation, shown below, can be used to calculate the value of soil cohesion [17]:

$$
c=S_{u}+p \tan \varnothing
$$

Where $S_{u}$ is shear strength value, and $p$ is the effective pressure normal to the surface of failure. According to Canadian Foundation Engineering Manual [13], for short-term foundation stability, the value of $\varnothing=0$, so the value of $S_{u}$ becomes $c$. For crane work, as the crane stability is a short-term constraint, the value of $\varnothing=0$ for all the equations for allowable soil bearing capacity [13].

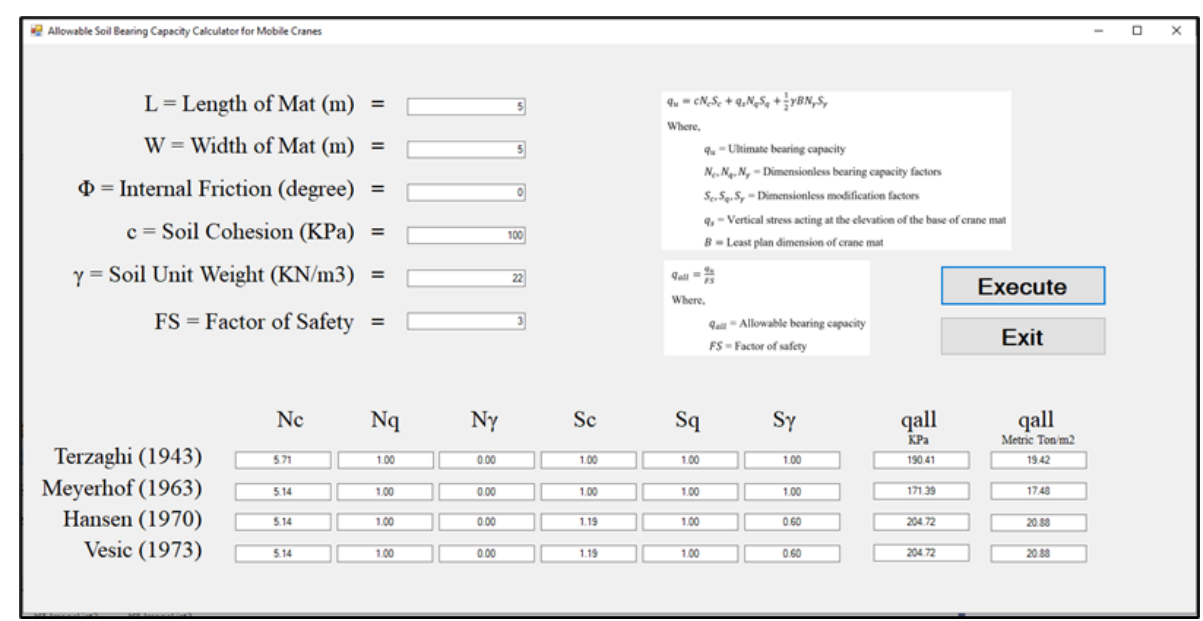

Fig. 4: Computer application $(A S B C)$ for calculating allowable ground bearing pressure for crane work.

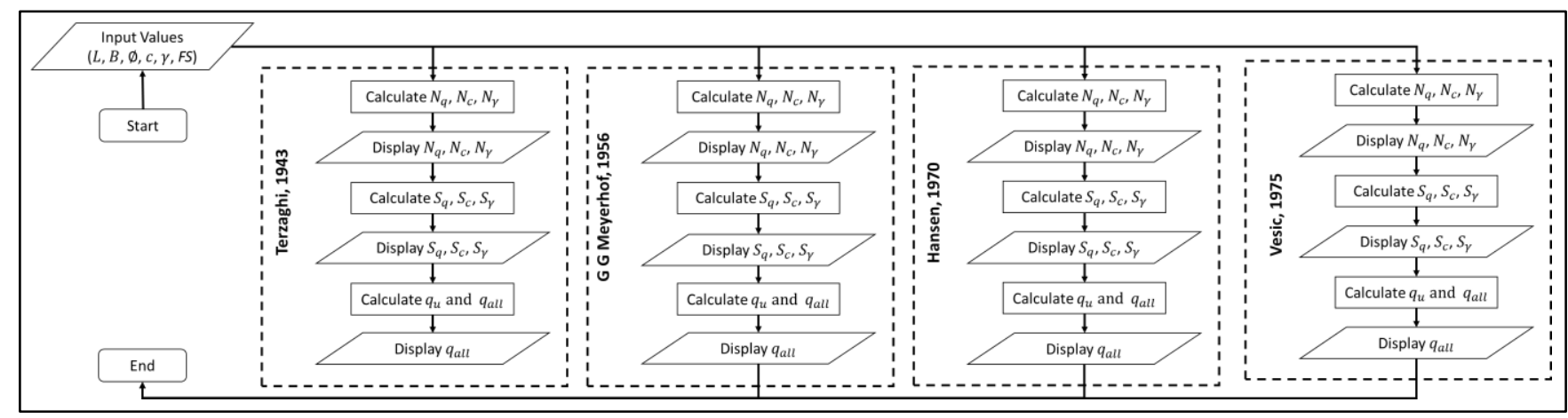

Fig. 5: Flowchart for allowable soil bearing capacity calculations ( $A S B C)$. 
Mostly, the value $\emptyset$ is zero, as the crane work falls under short-term loading. For the crane work over a long time (long-term foundation stability), the value $\emptyset$ is required and needs to be incorporated to obtain the allowable soil bearing capacity values. The geotechnical reports provide these values.

If the shear strength value is not available, Table 1 provides possible intervals for this parameter as a function of type [13]. Eq. 20 can be used to calculate the value of soil cohesion. Another aspect that needs attention is the value of soil weight $\gamma$, obtained using Table 2 [15]. The values of various soil types in Table 2 are tabulated into the saturated dry states. For the soil bearing capacity calculations, the saturated value is used in the application for short-term stability. For long-term usage, the practitioners can incorporate dry unit weight for allowable soil bearing capacity calculations.

The last piece of the puzzle is the value of soil friction angle $\emptyset$. Ortiz et al. [18] developed a table with the values of soil friction for various types of soils, as shown in Table 3. The practitioners can use the values from Table 3 to calculate the allowable soil bearing capacity.

Table 1: Values of undrained shear strength of various soil types.

\begin{tabular}{|c|c|c|}
\hline & Soil Type & Undrained shear strength $S_{u}$ value $(\mathrm{KPa})$ \\
\hline 1 & Very soft & $<12$ \\
\hline 2 & Soft & 12 to 25 \\
\hline 3 & Medium Stiff & 25 to 50 \\
\hline 4 & Stiff & 50 to 100 \\
\hline 5 & Very Stiff & 100 to 200 \\
\hline 6 & Hard & 200 to 300 \\
\hline 7 & Very Hard & $>300$ \\
\hline \multicolumn{2}{|c|}{$\begin{array}{l}\text { Sources: Data adapted from Canadian Geotechnical Society Foundations Committee. (1985). } \\
\text { Canadian foundation engineering manual. Canadian Geotechnical Society }\end{array}$} \\
\hline
\end{tabular}

Table 2: Values of undrained shear strength of various soil types.

\begin{tabular}{|c|l|c|c|}
\hline \multirow{2}{*}{ Description } & \multicolumn{2}{|c|}{ Unit Weight $\left(\mathrm{KN} / \mathrm{m}^{3}\right)$} \\
\cline { 2 - 3 } & & $\gamma$ (dry) & $\gamma($ saturated $)$ \\
\hline 1 & Uniform sand, loose & 14.1 & 18.5 \\
\hline 2 & Uniform sand, dense & 17.1 & 20.4 \\
\hline 3 & Mixed-grained sand, loose & 15.6 & 19.5 \\
\hline 4 & Mixed-grained sand, dense & 18.2 & 21.2 \\
\hline 5 & Windblown silt (loess) & 13.4 & 18.2 \\
\hline 6 & Glacial silt, very mixed-grained & 20.4 & 22.8 \\
\hline 7 & Soft glacial clay & 11.9 & 17.3 \\
\hline 8 & Stiff glacial clay & 16.7 & 20.3 \\
\hline 9 & Soft, slightly organic clay & 9.1 & 15.4 \\
\hline 10 & Soft, very organic clay & 6.8 & 14.0 \\
\hline 11 & Soft montmorillonitic clay (calcium bentonite) & 4.2 & 12.6 \\
\hline Sources: Data adapted from Ralph B. Peck, Hanson, W. E., \& Thornburn, T. H. (1974). Foundation engineering (2nd ed.). Wiley. \\
\hline
\end{tabular}

\subsection{Case Example (soil friction angle $=0$ )}

For uniform sand ( $\approx$ dense), the value of $\gamma$ is $20 \mathrm{KN} / \mathrm{m}^{3}$ (Table 2). Since the value of $S_{u}$ is the same as of $c$, so for very stiff soil, the value of $c$ is taken as $150 \mathrm{KPa}$. The values are incorporated in the application to obtain the allowable soil bearing capacity. Before that, the dimensions of the crane track/outrigger/mat are essential. For this case example, the length $L$ is $10 \mathrm{~m}$, but the width $B$ is considered variable from $1,2, \ldots, 10 \mathrm{~m}$. This variation of width helps to generate a sensitivity analysis to observe the variation of allowable soil bearing capacity along $B / L$ as shown in Figure 6(a). The $F S$ is 3 for this case example (between 2 5). 
The graphical representation shows that the allowable soil bearing capacity values generated using Hansen (1970), and Vesic (1973) increases as the $B / L$ reaches 1 . With the increase in value of $B$, the value of allowable soil bearing capacity also increases. On the other hand, the values generated using Terzaghi (1943) and Meyerhof (1963) remain constant. The constant value of allowable bearing capacity with Terzaghi (1943) and Meyerhof (1963) is due to the values of $S_{q} \& S_{\gamma}$. With $\varnothing=0$, the conservative approach takes the minimum value of allowable soil bearing capacity for ground preparation.

\subsection{Case Example (soil friction angle=6)}

If the crane work is long-term at one location, the value $\emptyset$ is incorporated in the application for the allowable soil bearing capacity calculations. For the soil composed of clay, high plasticity, the value of $\emptyset=6$ is taken by the author for this case example for the allowable soil bearing capacity calculations. All other values are the same as the case example with $\emptyset=0$.

The graphical representation, Figure 6(b), shows that all the four approaches generate ascending values along $B / L$. The slope of allowable soil bearing capacity along $B / L$ of Hansen (1970) and Vesic (1973) is more significant as compared to Terzaghi (1943) and Meyerhof (1963). The results also show that when the value of $B$ increases, the allowable soil bearing capacity also increases, regardless of the approach used for the calculations.

Table 3: Typical friction angle values (degree) for various soil types.

\begin{tabular}{|c|l|c|}
\hline & Description & Friction angle $\emptyset$ (Degree) \\
\hline 1 & Gravel & $32 \sim 34$ \\
\hline 2 & Gravel, sandy with few fines & $32 \sim 35$ \\
\hline 3 & Gravel, sandy with silty or clayey fines & $32 \sim 35$ \\
\hline 4 & Gravel and sand mixture, with fines & $22 \sim 28$ \\
\hline 5 & Sand, uniform, fine grained & $30 \sim 32$ \\
\hline 6 & Sand, uniform, coarse grained & $30 \sim 34$ \\
\hline 7 & Sand, well graded & $32 \sim 33$ \\
\hline 8 & Silt, low plasticity & $25 \sim 28$ \\
\hline 9 & Silt, medium to high plasticity & $22 \sim 25$ \\
\hline 10 & Clay, low plasticity & $20 \sim 24$ \\
\hline 11 & Clay, medium plasticity & $10 \sim 20$ \\
\hline 12 & Clay, high plasticity & $6 \sim 17$ \\
\hline 13 & Organic Silt or Clay & $15 \sim 20$ \\
\hline $\begin{array}{l}\text { Sources: Data adapted from Ortiz, J.M.R., Mazo, C.O., Gesta, J.S., and de Arquitectos de Madrid, C.O. } 1986 . \\
\text { Curso aplicado de cimentaciones. In 3rd edition. Colegio Oficial de Arquitectos de Madrid. }\end{array}$ \\
\hline
\end{tabular}

(a)

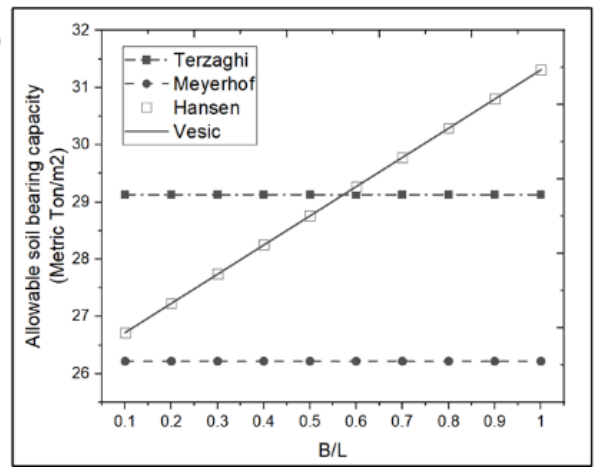

(b)

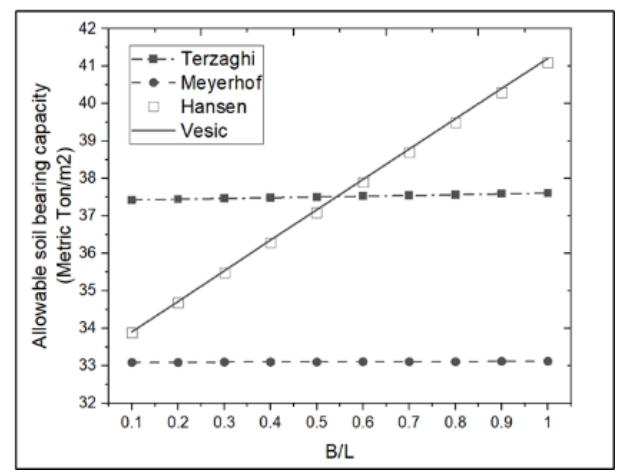

Fig. 6(a): Variation of allowable soil bearing capacity $q_{\text {all }}$ along $B / L\left(\varnothing=0, \gamma=20 \mathrm{KN} / \mathrm{m}^{3}, c=150 \mathrm{KPa}, L=10 \mathrm{~m}, B=1,2,3 \ldots, 10 \mathrm{~m}\right)$, 6(b): Variation of allowable soil bearing capacity $q_{\text {all }}$ along $B / L\left(\varnothing=6, \gamma=20 \mathrm{KN} / \mathrm{m}^{3}, c=150 \mathrm{KPa}, L=10 \mathrm{~m}, B=1,2,3 \ldots, 10 \mathrm{~m}\right)$.

\section{Discussion, Conclusion, and Future Aspects}

In both case examples, the results show that the change in the width of the crane track/outrigger/mat changes the allowable soil bearing capacity value. This outcome contradicts the traditional approach of obtaining a single allowable soil 
bearing capacity from a client for crane work. A single value of allowable soil bearing capacity can be misleading, as the width of the crane track/outrigger/mat varies. Using a conservative value from all four approaches is advisable to estimate ground preparation for crane work. The author of this contribution expects that in the future, more approaches shall be incorporated in this application to estimate the allowable soil bearing capacity for crane work. For future validation, the use of finite element analysis can be helpful. The use of finite element analysis can further elaborate and portray the soil behavior under the crane footing.

\section{References}

[1] J. Wilson, "The Potential of Prefab: How Modular Construction Can Be Green," Building Green, 2019. [Online]. Available: https://www.buildinggreen.com/feature/potential-prefab-how-modular-construction-can-be-green.

[2] A. W. A. Hammad, A. Akbarnezhad, P. Wu, X. Wang, and A. Haddad, "Building information modelling-based framework to contrast conventional and modular construction methods through selected sustainability factors," J. Clean. Prod., vol. 228, pp. 1264-1281, 2019, DOI: https://doi.org/10.1016/j.jclepro.2019.04.150.

[3] J. Beavers, J. R. Moore, R. Rinehart, and W. R. Schriver, "Crane-Related Fatalities in the Construction Industry," J. Constr. Eng. Manag. - J CONSTR ENG Manag., vol. 132, pp. 901-910, 2006, DOI: 10.1061/(ASCE)07339364(2006)132:9(901).

[4] P. Du, X. Liu, and Y. Zhang, "Discussion of the Method to Determine the Ultimate Bearing Capacity of Soil Foundation," \{IOP\} Conf. Ser. Earth Environ. Sci., vol. 100, p. 12007, Dec. 2017, DOI: 10.1088/1755$1315 / 100 / 1 / 012007$.

[5] K. Terzaghi, Theoretical Soil Mechanics. John Wiley, 1943.

[6] G. G. Meyerhof, "Some Recent Research on the Bearing Capacity of Foundations," Can. Geotech. J., vol. 1, no. 1, pp. 16-26, 1963, DOI: 10.1139/t63-003.

[7] J. B. Hansen, "A revised and extended formula for bearing capacity," Bulletin No. 28, Danish Geotechnical Institute, Copenhagen, 1970.

[8] A. S. Vesic, "Bearing Capacity of Shallow Foundations," in Foundation Engineering Handbook, 1st ed., New York, N.Y.: Van Nostrand Reinhold, New York, 1975, pp. 121-147.

[9] K. C. Onyelowe, "Mathematical advances in soil bearing capacity," Electron. J. Geotech. Eng., vol. 22, no. 12, pp. 4735-4743, 2017.

[10] A. Gaonkar, S. Arondekar, A. Mungarwadi, P. Gaude, V. Gaude, V. Haldankar, S. Sail, and A. Kudchadkar, "Estimation of Ultimate Bearing Capacity of Soil for Shallow Foundation," in Recent Trends in Civil Engineering, 2021, pp. 305316.

[11] K. Patwardhan and S. Metya, "A Comparative Study on Commonly Used Methods for Calculating Bearing Capacity in Shallow Foundation," Adv. Sustain. Constr. Mater. Sel. Proc. ASCM 2020, vol. 124, p. 167, 2021.

[12] A. Tahmid, S. Junaed, and A. S. M. F. Hossain, "A Comparative Study of Measuring Soil Bearing Capacity for Shallow Foundations Using Analytic Approaches and Empirical Formulas with SPT at Various Locations of Dhaka City," $J$. Remote Sensing, Environ. Sci. Geotech. Eng., vol. 6, no. 2, pp. 23-32, 2021.

[13] Canadian Geotechnical Society Foundations Committee, Canadian foundation engineering manual. Canadian Geotechnical Society., 1985.

[14] D. P. Coduto, Foundation design : principles and practices., 2nd ed. Prentice-Hall, 2001.

[15] Ralph B. Peck, W. E. Hanson, and T. H. Thornburn, Foundation engineering, 2nd ed. New York: Wiley, 1974.

[16] G. G. Meyerhof, "Penetration tests and bearing capacity of cohesionless soil," J. Soil Mech. Found. Div., vol. 82, pp. $1-19,1956$.

[17] H. Yokoi, "Relationship between soil cohesion and shear strength," Soil Sci. Plant Nutr., vol. 14, no. 3, pp. 89-93, 1968, doi: 10.1080/00380768.1968.10432750.

[18] J. M. R. Ortiz, C. O. Mazo, J. S. Gesta, and C. O. de Arquitectos de Madrid, Curso aplicado de cimentaciones, 3rd ed. Colegio Oficial de Arquitectos de Madrid, 1986. 